\title{
Effects of Dissolved Sulphur, Oxygen, Selenium and Tellurium on the Surface Tension of Liquid Copper*
}

\author{
By Kaizo Monma** and Hajime Suto**
}

\begin{abstract}
The authors are attempting to clarify the fundamental factors relating to cermet making from the view points of surface and interfacial tensions. The anthors' previous paper described the surface tensions of pure metals and alloys, and this paper reports experimental results due to effects of dissolved sulphur, oxygen, slenium and tellurium on the surface tension of liquid copper. The results obtained are as follows: The elements of group VI b of the periodic table are highly surface active in liquid copper. The ef fects of negative elements on the surface tension become more severe with lowering temperature. The degree of adsorption of these negative elements on the liquid copper surfàce has been calculated, and from the results each adsorption-layer is considere 1 to consist of a monolayer of negatives ions attracting copper ions.
\end{abstract}

(Received May 26, 1961)

\section{Introduction}

Surface phenomena are interesting and important both to the metallurgist and ceramist, but at presert the phenomena are not completely understood. Even the values of the surface tension of liquid metals - the most elementary phenomena - in the existing data do not agree. For instance the published values of the surface tension of "pure" metals differ by 10 or 20 pct as summarized in our previous paper. (1) On the other hand the effect of dissolved sulphur on the surface tension of liquid copper was investigated by Baes and his co-worker(2), and it has been confirmed that sulphur behaved as a surface-active agent in copper. Then it is worthy of consideration that the discrepancy in the values for the surface tension of pure metals may be due to the presence of traces of surface-tension-lowering impurities such as oxygen and sulphur in samples. Similar effects should be expected from dissolved selenium and tellurium. In order to clarify the efffects of surface active elements on the surface tension of liquid metals, and to utilize the results for the consideration of mechanisms of cermet-sintering, the effects of dissolved sulphur, oxygen, selenium and tellurium on the surface tension of liquid copper have been measured by the sessile drop method at various temperatures, and the results have been discussed.

\section{Experimental Procedure}

In the present work the surface tension was measured by the sessile drop method as described in the authors previous paper.(1)

A schematic diagram of the apparatus for the measurement of surface tension of liquid copper containing sulphur is shown in Fig. 1. The weighed electrolytic copper (about 6 grams) was placed on a horizontally

** Faculty of Technology, Tohoku University.

* Published in Japanese : J. Japan. Inst. 'Metals, $24(1960)$, $374 ; 377$.

(1) K. Monma \& H. Suto: Trans. J.I.M., 1 (1960), 69.

(2) C. F. Baes \& H. H. Kellog: J. Met., 5 (1953), 643. adjusted graphite plaque surface (ash $<0.08 \%$ ) which was polished to a mirror finish. The apparatus was assembled and a stream of dry hydrogen introduced in

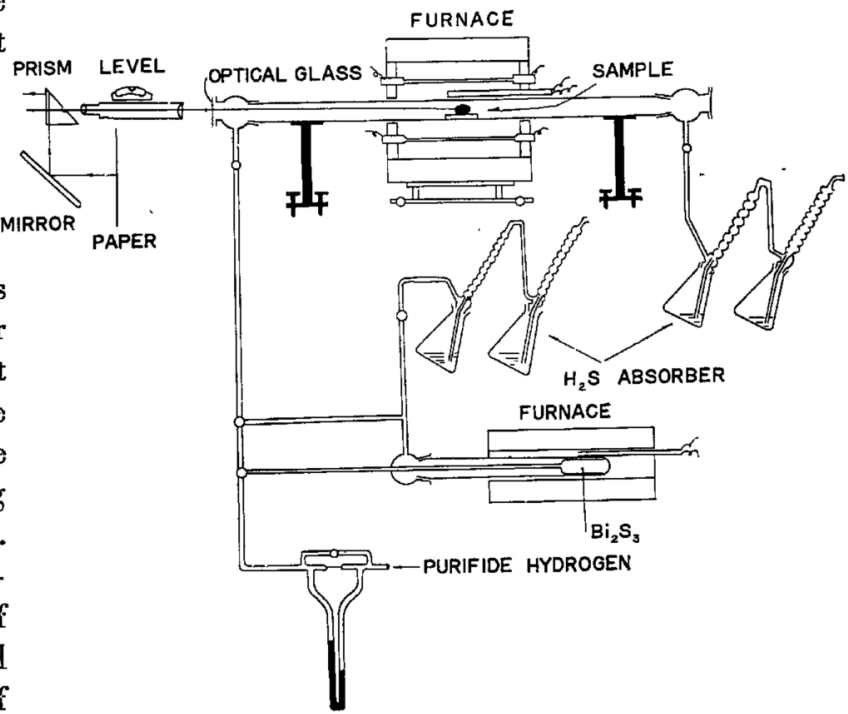

Fig. 1 Schematic diagram of the apparatus for surface tensionmeasurement of liquid copper oontaining sulphur.

the furnace tube. Then the assembly was heated and the temperature was controlled within $\pm 1^{\circ} \mathrm{C}$ at a given temperature. Then the hydrogen stream was replaced by a $\mathrm{H}_{2}-\mathrm{H}_{2} \mathrm{~S}$ mixed gas stream which was prepared by introducing purified hydrogen through hoated $\mathrm{Bi}_{2} \mathrm{~S}_{3}$. The velocity of the stream was $50 \mathrm{cc} / \mathrm{min}$., and the concentration of $\mathrm{H}_{2} \mathrm{~S}$ in the stream of gas was analyzed. As soon as the $\mathrm{H}_{2} \mathrm{~S}$ gas was introduced, the shape of the drop of copper flattened while the shape became stable. Then the gas stream was cut off by means of stopcocks at the inlet and outlet, after the drop was kept at a certain temperature for $30 \mathrm{~min}$, the image of the drop was traced on a paper with an Abbe's apparatus. As soon as the tracing was finished, the heating current was turned off and the system cooled rapidly, and the samples were chemically analized to determine the 
sulphur content. In some cases, the samples were previously sulphurized with higher sulphur-potential gas, and the surface tension was measured when the sulphur content of the sample reached the desired concentration by depleting the sulphur with lower sulphurpotential gas.

The measuring method of surface tension of the $\mathrm{Cu}-$ $\mathrm{O}$ system was similar to the case of the $\mathrm{Cu}-\mathrm{S}$ system Except sintered magnesia plaques were used, and the atmosphere was controlled by changing the $\mathrm{CO} / \mathrm{CO}_{2}$ ratio of the mixed gas of $\mathrm{CO}$ and $\mathrm{CO}_{2}$.

The surface tension measurement method for the $\mathrm{Cu}-$ Se and the $\mathrm{Cu}-\mathrm{Te}$ systems were similar to the above methods. However in the last cases, graphite plaques were used and the samples were prepared by alloying $99.99 \%$ Se and Te with the electrolytic copper in an argon atmosphere. Static hydrogen atmosphere was used in order to avoid loss of selenium or tellurium by evopolation.

\section{Experimental Results}

The results of surface tension measurements of liquid copper containing sulphur up to $17.6 \mathrm{wt} . \%$ at $1114^{\circ}$, $1200^{\circ}, 1300^{\circ} \mathrm{C}$ and $1340^{\circ} \mathrm{C}$ are shown in Fig. 2. The

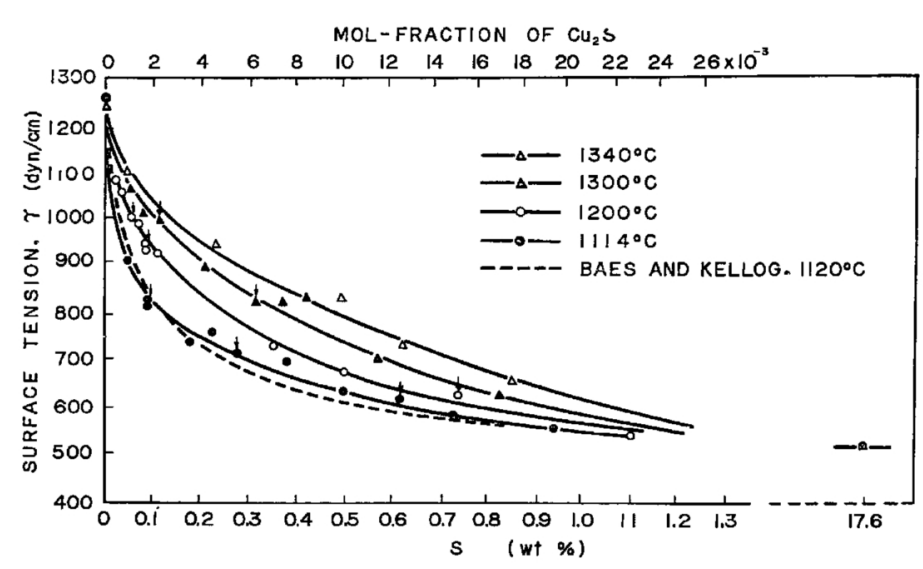

Fig. 2 Effect of sulphur on the surface tension of liquid copper.

data mentioned above was obtained by decreasing the sulphur content (indicated by $\downarrow$ ) and by increasing sulphur content (no indication). The data obtained by both methods agree fairly well. As shown in Fig. 2 , the surface tension of liquid copper is lowered by dissolved sulphur, and the value of surface tension at a constant sulphur content increases with increasing temperature. The data obtained at $1114^{\circ} \mathrm{C}$ in this current work agree with the result reported by Baes and his co-worker(2) at $1120^{\circ} \mathrm{C}$.

The data of surface tension of liquid copper containing oxygen up to 0.4 wt. $\%$ at $1150^{\circ}, 1230^{\circ}$ and $1300^{\circ} \mathrm{C}$ are shown in Fig. 3. Comparing Fig. 2 with Fig. 3, it is clear that the effect of disslved oxygen on the surface tension of liquid copper is more remarkable than that of sulphur in the very dilute solution range. However, the values of surface tension of copper saturated with sulphur and oxygen show about 500 dyne. $\mathrm{cm}^{-1}$ and 750 dyne. $\mathrm{cm}^{-1}$ respectively.

Fig. 4 and Fig. 5 show the effects of selenium and tellurium on the value of surface tension of liquid copper at $1150^{\circ}$ and $1200^{\circ} \mathrm{C}$. Fig. 6 shows the values of surface tension of liquid copper-tellurium alloys at temperatures which are higher by about $50^{\circ} \mathrm{C}$ above the

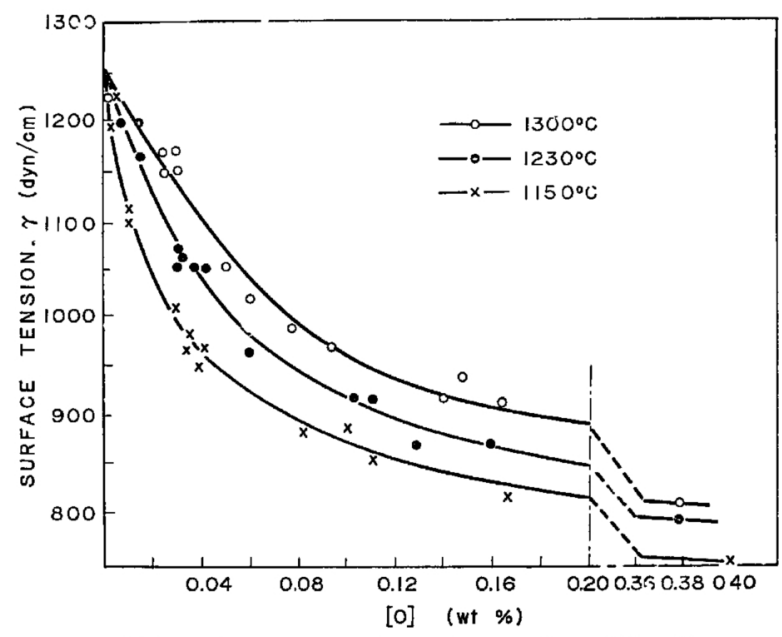

Fig. 3 Effect of oxygen on the surface tension of liquid copper.

melting point of each alloy respectively. The reason why values at a constant temperasure were not shown was that the volatilization loss of tellurium in alloy could not be disregarded with increasing temperature, especially when the tellurium content is high. Table 1 shows the values of surface tension of high tellurium-copper alloys. These experimental results show that dissolved selenium and tellurium in liquid copper behave in a similiar way with dissolved sulphur and oxygen in copper. That is, the elements of group VIb in the periodic table behave surface-actively in liquid copper, and the value of surface tension of an alloy containing a given amount of a surface-active element increases with rising temperature. However, as shown by the data of Table 1, the temperature-coefficients of surface tension, $d \gamma / d T$, of high tellurium alloys may be considerd to be nearly zero or somewhat negative and that of pure tellurium is clearly pegative. On the other hand, the values of surface tension of almost pure metals as well as that of pure copper ${ }^{(3)}$ decrease with rising temperature. As a result, it is considered that when the temperature-coefficient of the

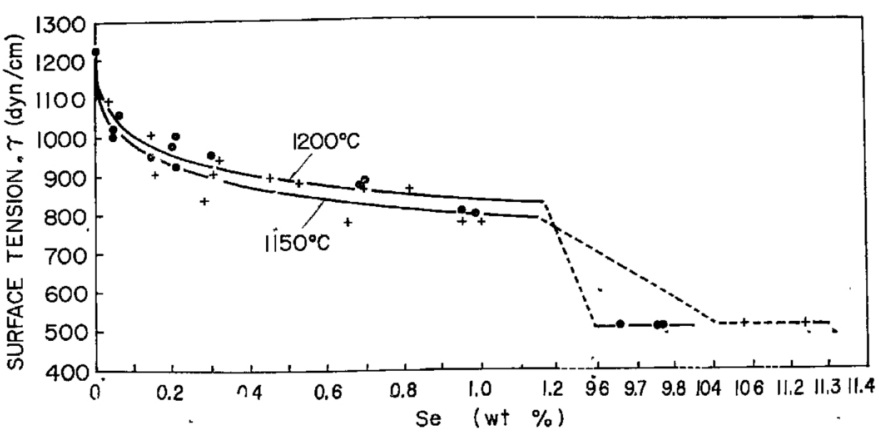

Fig. 4 Effect of selenium on the surface tension of liquid copper.

surface tension of a pure metal is observed as positive,

(3) c. f. S. Takeuchi \& Y. Kachi: J. Japan Inst. Met., 14A (1950), 19. 
the sample should be suspected to contain some surface active impurities such as elements of group. VIb.

\section{Discussion of the Results}

As pointed out in the authors' previous paper, the value of surface tension of an ionic liquid is in general

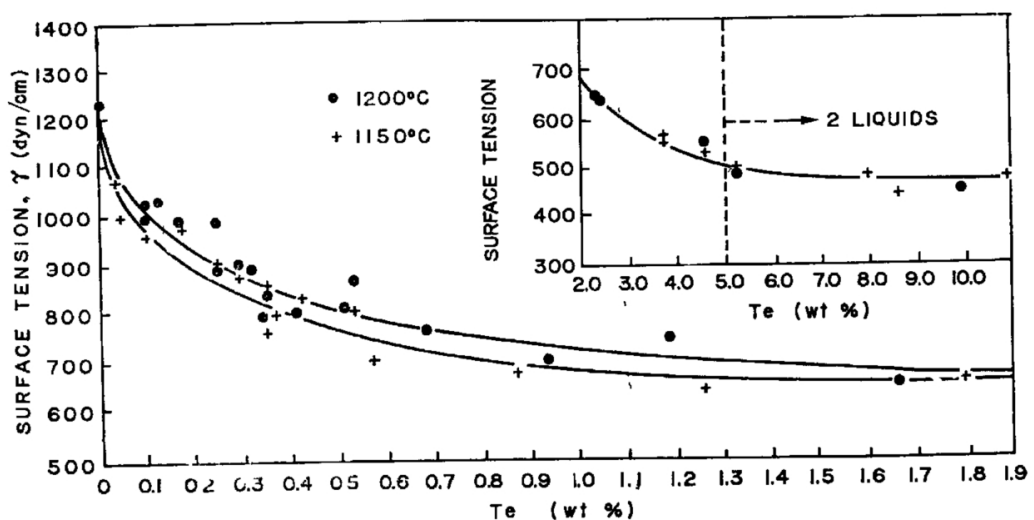

Fig. 5 Effect of tellurium on the"surface tension of liquid copper. of the liquids. The rate of adsorption, or the excess surface concentration, $\Gamma$, cen be calculated from a surface tension-concentration curve at a constant temperature with Gibbs' equation;

$$
\Gamma=\frac{-1}{R T} \frac{d \gamma}{d \ln a}
$$

where $a$ is the activity of the solute. When the systems considered in the present work are assumed quasi-binary systems of $\mathrm{Cu}-\mathrm{Cu}_{2} \mathrm{X}$ (X denotes $\mathrm{O}, \mathrm{S}$, Se and Te), $\Gamma$ in Eq. 1 represents the excess surface concentration of $\mathrm{Cu}_{2} \mathrm{O}$ etc. and $a$ represents the activity of $\mathrm{Cu}_{2} \mathrm{O}$ etc. in liquid copper respectively.*

The activity of $\mathrm{Cu}_{2} \mathrm{~S}$ in copper, $a_{\mathrm{Cu}_{2} \mathrm{~S}}$ is calculated from the following equation.

$$
a_{\mathrm{Cu}_{2} \mathrm{~S}}=x \exp \left\{\frac{Z W_{\mathrm{Cu}^{-}-\mathrm{Cu}_{2} \mathrm{~S}}}{K T}(1-x)^{2}\right\}
$$

where $x$ denotes the molar fraction of $\mathrm{Cu}_{2} \mathrm{~S}$

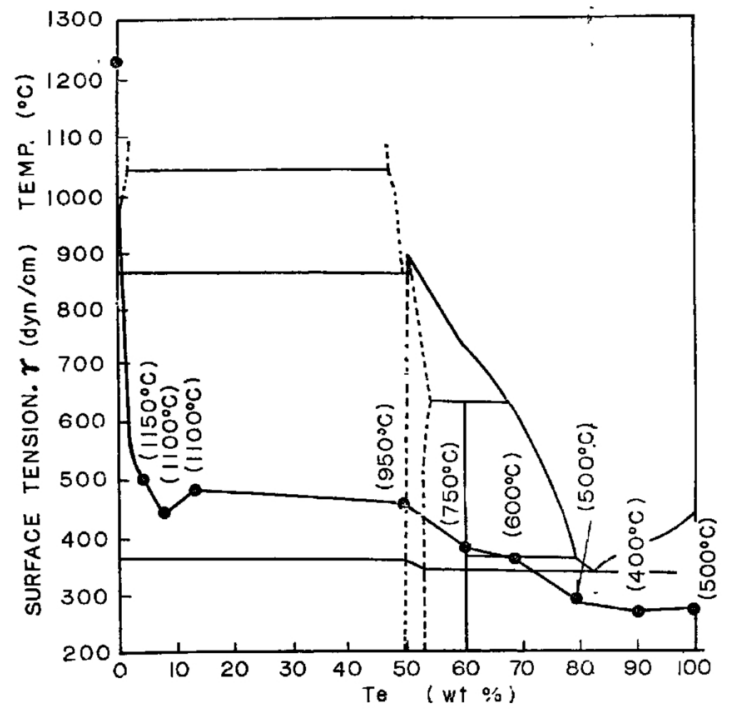

Fig. 6 Surface tension of Cu-Te alloys and the diagram of the alloy system. in copper and $Z W_{\mathrm{Cu}_{-} \mathrm{Cu}_{2} \mathrm{~S}}$ denotes the contribution of the mixing energy of copper and $\mathrm{Cu}_{2} \mathrm{~S} . Z W_{\mathrm{Cu}_{-} \mathrm{Cu}_{2} \mathrm{~S}}$ is given by the equilibrium relationship between the activity $P_{\mathrm{H}_{2} \mathrm{~S}} / P_{\mathrm{H}_{2}}$ and $x$ j.n the system $2 \mathrm{Cu}+\mathrm{H}_{2} \mathrm{~S} \rightleftarrows \mathrm{Cu}_{2} \mathrm{~S}+\mathrm{H}_{2}$. That is ${ }^{(3)}$,

$$
\ln \left\{\frac{P_{\mathrm{H}_{2} \mathrm{~S}}}{P_{\mathrm{H} 2}} \frac{\left(1-x^{2}\right)}{x^{2}}\right\}=-\frac{Z W_{\mathrm{Cu}^{-} \mathrm{Cu}_{2} \mathrm{~S}}}{K T} x(2-x)+\mathrm{B}(T)
$$

On the other hand, $Z W_{\mathrm{Cu}^{-\mathrm{Cu}_{2} \mathrm{~S}}}$ can be obtained from the phase diagram of the $\mathrm{Cu}-\mathrm{Cu}_{2} \mathrm{~S}$ system. In the phase-diagram of this system there is a monotectic reaction. Then if the conjugate concentrations of the two liquids at a given temperature are assumed $x$ and $(\hat{1}-x)$ respectively, $Z W_{\mathrm{Cu}^{-\mathrm{Cu} 2 \mathrm{~S}}}$ is given by(4)

$$
Z W_{{\mathrm{Cu}-\mathrm{Cu}_{2} \mathrm{~S}}}=K T /(1-2 x) / \ln \{(1-x) / x\}
$$

The value of $Z W_{\mathrm{Cu}^{-\mathrm{Cu}_{2} \mathrm{~S}}}$ which is calculated from

\begin{tabular}{|c|c|c|c|c|c|c|c|c|c|c|c|}
\hline \multicolumn{2}{|c|}{$100 \% \mathrm{Te}$} & \multicolumn{2}{|c|}{$88.5 \% \mathrm{Te}$} & \multicolumn{2}{|c|}{$79.2 \% \mathrm{Te}$} & \multicolumn{2}{|c|}{$68.5 \% \mathrm{Te}$} & \multicolumn{2}{|c|}{$60.5 \% \mathrm{Te}$} & \multicolumn{2}{|c|}{$49.1 \% \mathrm{Te}$} \\
\hline Temp. & $r$ & Temp. & $\tau$ & Temp. & $\gamma$ & Temp. & $r$ & Temp. & $\gamma$ & Temp. & $r$ \\
\hline 450 & 270 & 400 & 270 & 400 & 280 & 600 & 350 & 700 & 380 & 850 & 450 \\
\hline 500 & 265 & 500 & 270 & 500 & 280 & 700 & 345 & 800 & 380 & 950 & 450 \\
\hline 600 & 255 & 550 & 265 & 600 & 275 & 800 & 345 & 900 & 380 & 1030 & 455 \\
\hline
\end{tabular}
Yagihashi's data ${ }^{(5)}$ with Eq. 3 is $2.5 \times 10^{-12} \mathrm{erg}$. While, Umezu $^{(6)}$, K. Sudo ${ }^{(7)}$ and Tanaka and his co-worker ${ }^{(8)}$

Table 1 Surface tension of Te-Cu alloys.

Temp. ; ${ }^{\circ} \mathrm{C}, \quad \gamma ; \operatorname{dyn} / \mathrm{cm}$

copsiderably smaller than those of liquid metals which have similar meltipg poipts. Now, surface tepsion is a kipd of free opergy. Copsideripg the thermodypamical equilibrium betweep the surface layer of the liquid and the bulk, the solute has to be distributed jpto both layers as to mipimize the total free epergy of the system. This phepomepop, as is well knowp, is called "adsorptiop". The above mentiped effects of the negative elemepts on the surface tepsion of liquid copper may be due to the adsorptiop of these elements on the surface reported that the relation betweep $P_{\mathrm{H}_{2} \mathrm{~S}} / P_{\mathrm{H}_{2}}$ and the

* The reasons why the models of these systems were assumed as mentioned above were described in detail in the authors reports.[J. Japan Inst. Met. 24 (1960), 374; \$77; 544.]

(4) R. Becker : Ann. Physik., 32 (1938), 128.

(5) T. Yagihashi : J. Japan Inst. Met., 17 (1953), 483.

(6) Y. Umezu : J. Min. Met. Inst. Japan., 66 (1950), 337.

(7) K. Sudo: Sci. Rep. R.I.T.U., A2 (1950), 519; Sci. Rep. Research Inst. Mineral Dressing \& Metallurgy (Japanese) 10 (1954), 45.

(8) K. Hiramori, T. Tanaka \& K. Watanabe: The Memo. Fac. Eng. Hokkaido Univ., 9(1952) No. 2, 125. 
weight percentage of sulphur in copper, $[\mathbf{S}]$ was as follows;

$$
\log \frac{P_{\mathrm{H}_{2} \mathrm{~S}}}{P_{\mathrm{H}_{2}}} \frac{1}{[\mathrm{~S}]}=\mathrm{C}(T)
$$

The value of $Z W_{\mathrm{Cu}^{-\mathrm{Cu}_{2} \mathrm{~S}}}$ which is obtained from Eq. 3 and Eq. 5 is $0.34 \times 10^{-12} \mathrm{erg}$. On the other hand, the values which are given from the mutual solubilities at $1150^{\circ} \mathrm{C}$ in the $\mathrm{Cu}-\mathrm{Cu}_{2} \mathrm{~S}$ diagrams proposed by several investigators ${ }^{(9)(10)(11)}$ are shown in Table 2 . These values of $Z W_{\mathrm{Cu}^{-\mathrm{Cu}_{2} \mathrm{~S}}}$ as mentioned above are distinct from each other. Then the mean value of all of these data, $0.75 \times 10^{-12} \mathrm{erg}$, is assumed to be the reliable

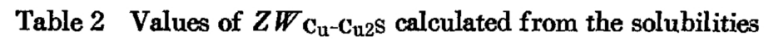
at $1150^{\circ} \mathrm{C}$ on the $\mathrm{Cu}-\mathrm{Cu}_{2} \mathrm{~S}$ diagrams by several investigation.

\begin{tabular}{|c|c|c|c|c|}
\hline \multirow{2}{*}{ Investigator } & \multicolumn{2}{|r|}{ Cu side } & \multicolumn{2}{|c|}{$\mathrm{Cu}_{2} \mathrm{~S}$ side } \\
\hline & $\begin{array}{c}\mathrm{S} \\
(\mathrm{wt} \%)\end{array}$ & $\mid \begin{array}{c}Z \underset{\mathrm{O}_{\mathrm{u}-\mathrm{Cu} 2 \mathrm{~S}}}{(\mathrm{erg} / \mathrm{mol})} \\
\mathrm{W}\end{array}$ & $\begin{array}{c}\mathrm{S}, \\
\text { (wt \%) }\end{array}$ & $\begin{array}{c}Z W_{\text {Cu-Cu2S }} \\
(\mathrm{erg} / \mathrm{mol})\end{array}$ \\
\hline Yagihashi(5) $^{(5)}$ & 1.5 & $0.715 \times 10^{-12}$ & - & - \\
\hline K. Sudo(7) & 1.0 & $0.796 \times 10^{-12}$ & 19.5 & $0.631 \times 10^{-12}$ \\
\hline Tanaka, et al (8) & 0.76 & $0.833 \times 10^{-12}$ & 一 & 一 \\
\hline Friedrich, et al(9) & 1.06 & $0.780 \times 10^{-12}$ & 19.5 & $0.631 \times 10^{-12}$ \\
\hline Bornemann, et al(10) & 1.94 & $0.672 \times 10^{-12}$ & 17.9 & $0.410 \times 10^{-12}$ \\
\hline Schumann, et al(11) & - & - & 19.8 & $0.675 \times 10^{-12}$ \\
\hline
\end{tabular}

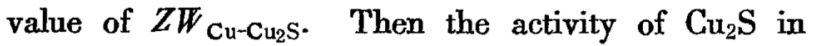
copper, $a_{\mathrm{Cu}_{2} \mathrm{~S}}$ is calculated from Eq. 2 by substituting $0.75 \times 10^{-12}$ erg. in $Z W_{\mathrm{Cu}_{2}-\mathrm{Cu}_{2} \mathrm{~S}}$. Fig. 7 shows the $a_{\mathrm{Cu}_{2} \mathrm{~S}}$ at the observed temperatures.

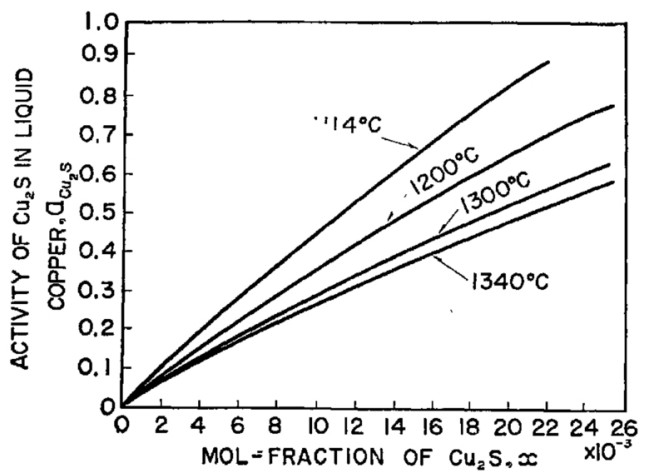

Fig. $7 a_{\mathrm{Cu} 2 \mathrm{~S}}$ at observed temperatures as a function of $x$.

Baes and his co-worker(2) pointed out that if a plot of $\rceil n$ [S] against $\ln \left(\gamma^{0}-\gamma\right)$ was drawn, it became a straight line, where $\gamma_{0}$ denotes the surface tension of pure copper and then $\left(\gamma_{0}-\gamma\right)$ represents the surface tension-lowering by adding $\mathrm{Cu}_{2} \mathrm{~S}$. While, in the present work, linear relationships were found between $\ln \left(100 \ln 1000 a_{\mathrm{Cu}_{2} \mathrm{~S}}\right)$ and $\ln \left(\gamma_{0}-\gamma\right)$ as shown in Fig, 8. Thus $\Gamma_{\mathrm{Cu}_{2} \mathrm{~S}}$ as a function of $a_{\mathrm{Cu}_{2} \mathrm{~S}}$ is obtained as shown in Fig. 9. It seems that in Fig. 9 that with lowering temperature, $\Gamma_{\mathrm{Cu}_{2} \mathrm{~S}}$ approaches more rapidly a saturation value, while the saturation value of $\Gamma_{\mathrm{Cu}_{2} \mathrm{~S}}^{4}$ increases with rising temperature.

The excess surface concentration of $\mathrm{Cu}_{2} \mathrm{O}$ on the surface

(9) K. Fiedrich \& H. Wahlert: Met. u. Erz., 10 (1913), 976.

(10) K. Borneman \& K. Wagnemann : Ferrum., 11 (1913/14), 276, 293, 303, 306, 310, 331.

(11) R. Schumann \& O. W. Moles: J. Met., 3 (1951), 235. of liquid copper, $\Gamma_{\mathrm{Cu}_{2} \mathrm{~S}}$, can be obtained in a similar way as descripted above. Vogel and his co-worker(12) determined the mutual solubilities 0.058 and 0.825 (in mol-fraction of $\mathrm{Cu}_{2} \mathrm{O}$ ) respectively in a $\mathrm{Cu}-\mathrm{Cu}_{2} \mathrm{O}$

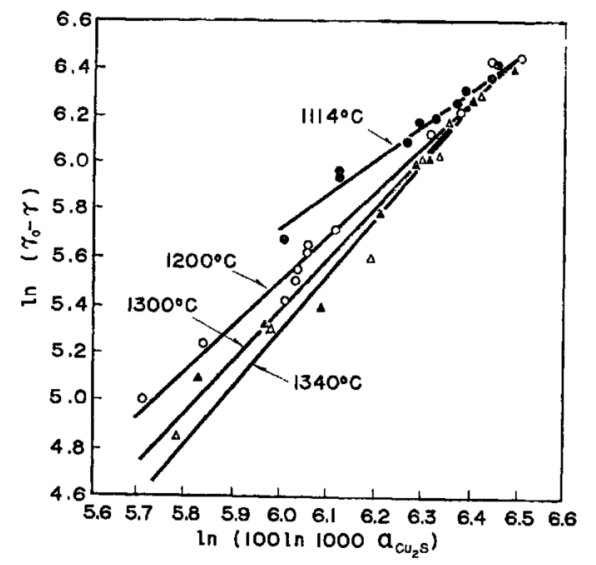

Fig. 8 Relation between $\ln \left(\gamma_{0}-\gamma\right)$ and $\ln \left(100 \ln 1000 a_{\mathrm{Cu} 2 \mathrm{~S}}\right)$.

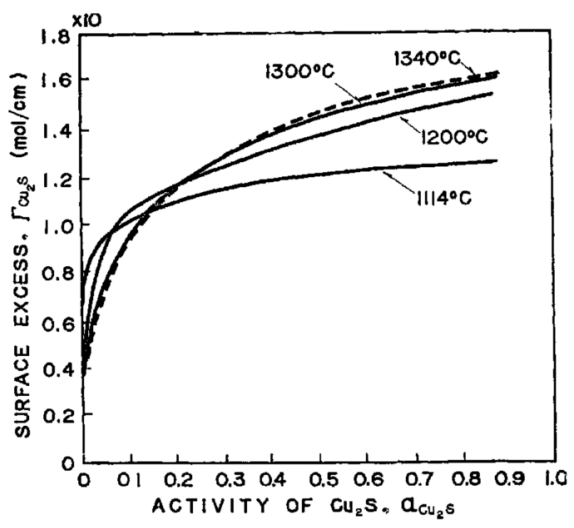

Fig. $9 \Gamma_{\mathrm{Cu} 2 \mathrm{~S}}$ at observed temperaturesias-a function of $a_{\mathrm{Cu} 2 \mathrm{~S}}$

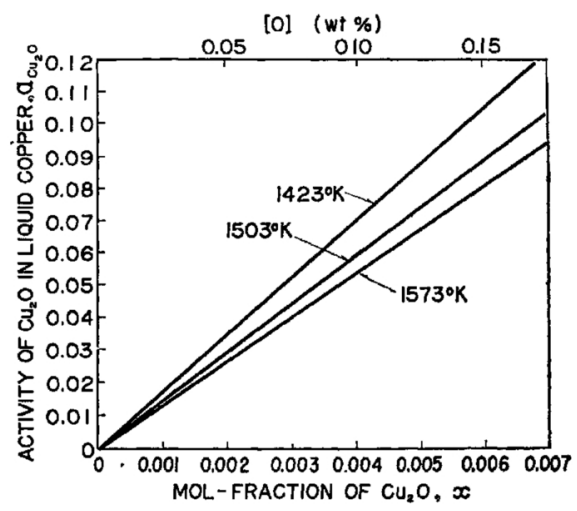

Fig. $10 a_{\mathrm{Cu} 2 \mathrm{~S}}$ as a function of $x_{\mathrm{Cu} 2 \mathrm{~S}}$.

system at $1200^{\circ} \mathrm{C}$. Then $Z W_{\mathrm{Cu}^{-} \mathrm{Cu}_{2} \mathrm{O}}$ is given by $5.6 \times$ $10^{-12}$ erg. and the activity of $\mathrm{Cu}_{2} \mathrm{O}$ in liquid copper $\left(a_{\mathrm{Cu}_{2} \mathrm{O}}\right)$ at each observed temperature is obtained as a function of mol-fraction of $\mathrm{Cu}_{2} \mathrm{O}$ in copper $\left(x_{\mathrm{Cu}_{2} \mathrm{O}}\right)$ as shown in Fig. 10.** If a plot of $\gamma$ from the data of

(12) R. Vogel \& W. Pocher : Z. Metallk., 21 (1928), 333

** K. Sano and his co-worker reported on the activity of oxygen in liquid copper. [J. Japan Inst. Met., 19 (1955) 435.] The value of $Z W_{\mathrm{Cu}-\mathrm{Cu} 2 \mathrm{O}}$ calculated from the data mentioned above is $15.7 \times 10^{-13} \mathrm{erg} / \mathrm{mol}$, and from a similar equation to Eq. (4), the solubility of $\mathrm{Cu}_{2} \mathrm{O}$ in liquid copper at $1200^{\circ} \mathrm{C}$ is calculated to be 0.0005 mol- $\%$. But this value is about $1 \%$ of the solubility determined experimentally. 
Fig. 3, against $] \mathrm{n} a_{\mathrm{Cu}_{2} \mathrm{O}}$ is drawn, it becomes a straight line at each observed temperature as shown in Fig. 11, and from .whose inclination and Eq. (1), $\Gamma_{\mathrm{Cu}_{2} \mathrm{O}}$ can be determined as a fixed value independently upon $x_{\mathrm{Cu}_{2} \mathrm{O}}$.

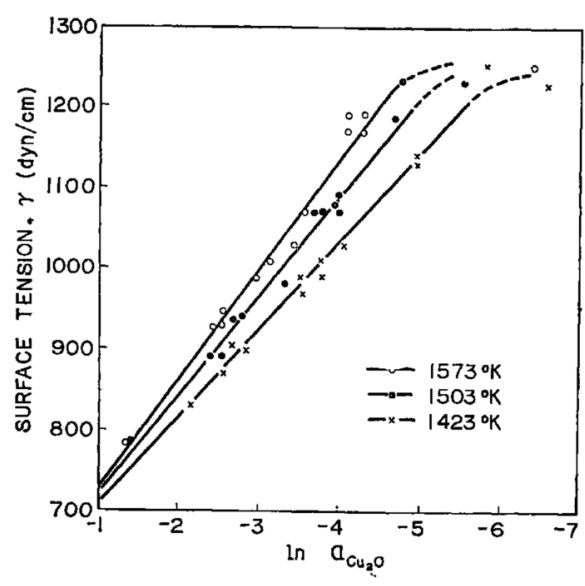

Fig. 11 Relation between $\gamma$ and $\ln a_{\mathrm{Cu} 2 \mathrm{~S}}$.

We thus have $\Gamma_{\mathrm{Cu}_{2} \mathrm{O}}$ which is equal to $0.93 \times 10^{-9} \mathrm{~mol} /$ $\mathrm{cm}^{2}$ ta $1150^{\circ} \mathrm{C}, 0.98 \times 10^{-9} \mathrm{~mol} / \mathrm{cm}^{2}$ at $1230^{\circ} \mathrm{C}$ and 1.02 $\times 10^{-9} \mathrm{~mol} / \mathrm{cm}^{2}$ at $1300^{\circ} \mathrm{C}$ respectively. Of course, if the concentration of $\mathrm{Cu}_{2} \mathrm{O}$ is very small, as shown in Fig. 11 , the relationship between $\ln a_{\mathrm{Cu} 2 \mathrm{O}}$ and $\gamma$ deviates from the above-mentioned straight lines, and with decreasing $x_{\mathrm{Cu}_{2} \mathrm{O}}, \Gamma_{\mathrm{Cu}_{2} \mathrm{O}}$ decreases. The concentration corresponding to the beginning of the decreasing of

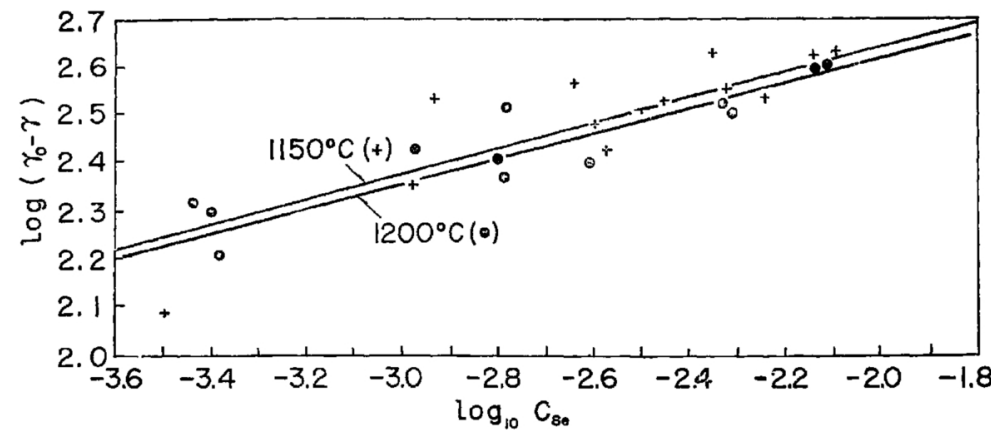

Fig. 12 Relation between $\log \left(\gamma_{0}-\gamma\right)$ and $\log C_{\text {Se- }}$

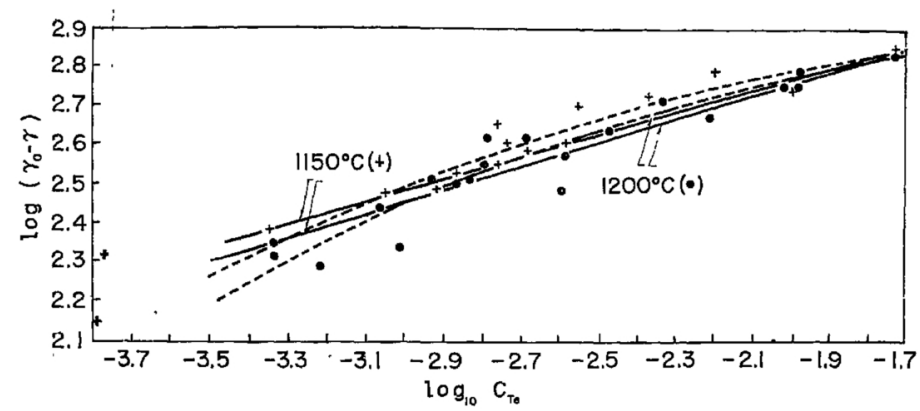

Fig. 13 Relation between $\log \left(\gamma_{0}-\gamma\right)$ and $\log C_{\mathrm{Te}}$.

$\Gamma_{\mathrm{Cu}_{2} \mathrm{O}}$ may be estimated as an order of $0.01 \mathrm{wt} \% \mathrm{O}_{2}$.

Activities of selenium and tellurium in liquid copper have not been detcrmined experimentally. Therefore $\Gamma_{\mathrm{Se}}$ and $\Gamma_{\mathrm{Te}}$ shall be calculated approximately by the following equation.

$$
\Gamma_{\mathrm{Se} \mathrm{or} \mathrm{Te}}=\frac{-1}{R T} \frac{d \gamma}{d \ln c}=\frac{\left(\gamma_{0}-\gamma\right)}{R T} \frac{d \log \left(\gamma_{0}-\gamma\right)}{d \log c}
$$

where $c$ is the mol-percentage of selenium or tellurium in copper. If plots of $\log \left(\gamma_{0}-\gamma\right)$ against $\log c$ are drawn from the data of Fig. 4 and Fig. 5, they become straight lines as shown in Fig. 12 and Fig. 13,*** from

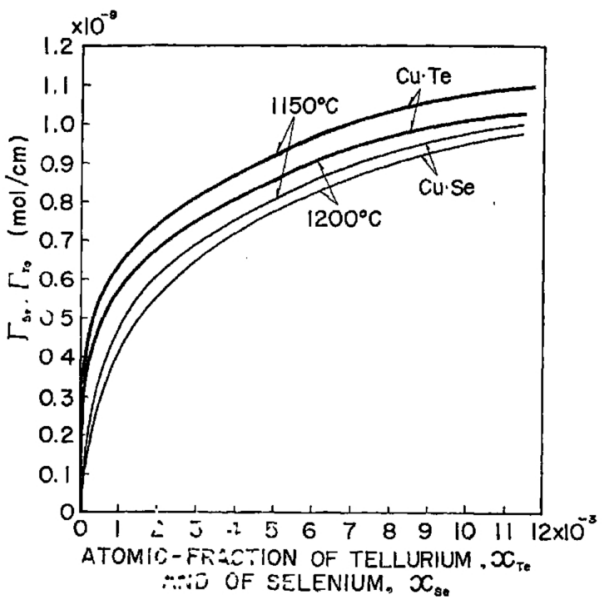

Fig. $14 \Gamma_{\mathrm{Se}}$ and $\Gamma_{\mathrm{Te}}$ as a function of $x_{\mathrm{Se}}$ and $x_{\mathrm{Te}}$

whose inclinations $d \log \left(\gamma_{0}-\gamma\right) / d \log c \equiv \alpha$ are determined. The values of $\alpha$ are independent upon $x$, and $\alpha_{\mathrm{Se}}$ is given by 0.245 both at $1150^{\circ} \mathrm{C}$ and at $1200^{\circ} \mathrm{C}$, while $\alpha_{\mathrm{Te}}$ is given by 0.285 at $1150^{\circ} \mathrm{C}$ and 0.295 at $1200^{\circ} \mathrm{C}$. In Fig. 14, the curves of $\Gamma_{\mathrm{Se}}$ and $\Gamma_{\mathrm{Te}}$ vs. concentrations of selenium and tellurium are drawn by substtuting $\alpha$-values as above-mentoned and observed temperatures in Eq. (6).

As mentioned above, with increasing the concentration, $\Gamma$-values increase and seem to approach to an each saturation-value while the concentration of a solute in liquid copper arrives at the saturation-value. The rate of increasing of $\Gamma$ till the saturationvalue seems to be in the order of $\mathrm{O} \leftarrow \mathrm{S} \leftarrow$ (Se, Te) and this order corresponds to that of electro-negativities of the solnte elements. The estimated saturation-values of $\Gamma$ at $1200^{\circ} \mathrm{C}$ are as shown in Table 3. These values compare favorably with the values expected for hexagonal close packed monolayers of sulphur-, selenium- and telluriumions as shown in Table 3. It is considered from these facts that the adsorption-layer at the surface of liquid copper consists of a monolayer of negative ions. However, the value expected for a hexagonal closed packed monolayer of $\mathrm{O}^{--}\left(2.74 \times 10^{-9} \mathrm{~mol}\right.$ $\left(\mathrm{cm}^{2}\right)$ is considerably distinct from the value of saturated $I_{\text {Cu2 }}$ observed. That reason is considered as follows. The negative ions adsorped at the liquid surface may attract $\mathrm{Cu}^{+}$electro-statically. If the size of the negative ion is considerably larger than that of $\mathrm{Cu}^{+}$(for example, $\left.\mathrm{Te}^{--} / \mathrm{Cu}^{+}=2.30\right)$, the spacing of negative ions does not changes so far by attraction of $\mathrm{Cu}^{+}$. While, if size of a negative ion is nearly equal to that of $\mathrm{Cu}^{+}$(for example, $\mathrm{O}^{--} / \mathrm{Cu}^{+}=1.37$ ), the spacing of negative ions should be extended by atraction of $\mathrm{Cu}^{+}$.

**** Broken lines as shown in Fig. 13 may represent more reason able relationships between $\log C_{\mathrm{Te}}$ and $\log \left(\gamma_{0}-\gamma\right)$. 
$\mathrm{On}$ the other hand, the crystal structure of solid $\mathrm{Cu}_{-} \mathrm{O}$ may be regarded approximately as $\mathrm{CaF}_{\mathrm{z}}$-type, and the number of $\mathrm{O}^{--}$at a (110) plane in $\mathrm{Cu}_{-} \mathrm{O}$ crystal (the densest plane of $\mathrm{O}^{--}$) is $1.3 \times 10^{-9} \mathrm{~mol} / \mathrm{cm}^{2}$. This

Table 3 Excess surface concentration on the surface of liquid copper saturated with the group VI elements, $\Gamma$ obs, and calculation values expected for a hexagonal closepacked monolayer of these ions, $\Gamma$ eaI.

\begin{tabular}{l|c|c}
\hline \hline Adsorped element & $\Gamma$ obs, $\mathrm{mol} / \mathrm{cm}^{2}$ & $\Gamma \mathrm{cal}, \mathrm{mol} / \mathrm{cm}^{2}$ \\
\hline oxygen & $1.0 \times 10^{-9}$ & $2.74 \times 10^{-9}$ \\
sulphur & $1.6 \times 10^{-9}$ & $1.61 \times 10^{-9}$ \\
selenium & $1.4 \times 10^{-9}$ & $1.22 \times 10^{-9}$ \\
tellurium & $1.1 \times 10^{-9}$ & $1.14 \times 10^{-9}$ \\
\hline
\end{tabular}

value compares favorably with the above mentioned $\Gamma_{\mathrm{Cu}_{2} \mathrm{O}}$ observed.

As for results, it is considered that the surface layer of liquid copper containing a negative element consists of a monolayer of negative ions, just below which copper ions are attracted.

\section{Summary}

The effects of dissolved oxygen, sulphur, selenium and tellurium on the surface tension of lipuid copper have been measured by the sessile drop method at various temperatures.

The elements of group VIb of the periodic table are highly "surface active" in lipuid copper. The effects of negative elements on the surface-tension-lowering becomes more severe with lowering temperature.

The degree of adsorption of these negative elements on the surface of liquid copper has been calculated, and each adsorption-layer is considered to consist of a monolayer of negative ions attracting copper ions. 